\title{
APUNTES SOBRE LA EVOLUCIÓN HISTÓRICA DE LA OBRA DE PEDRO ORTIZ CABANILLAS Y SU TEORÍA SOCIOBIOLÓGICA INFORMACIONAL
}

\author{
Hans Contreras-Pulache 1,2,a, Eduardo Espinoza-Lecca ${ }^{3,4, b}$, Javier Sevillano-Jimenez ${ }^{1, c}$
}

\begin{abstract}
RESUMEN
La Teoría Sociobiológica Informacional propone una definición radicalmente distinta de los sistemas vivos, y con lo mismo es la única teoría neurológica existente que evade el problema mente-cerebro y que explica la naturaleza de la conciencia humana. Fue desarrollada por Pedro Ortiz Cabanillas entre 1984 y 2011. En este documento vamos a realizar un recuento de todas sus obras más importantes. Incluimos, adicionalmente, material inédito de los años 1998, 1999, 2006, y 2009.
\end{abstract}

Palabras clave: Información; Teoría general de sistemas; Neocórtex; Paleocortex; Sociedad (fuente: DeCS BIREME)

\section{NOTES ON THE HISTORICAL EVOLUTION OF THE WORK OF PEDRO ORTIZ CABANILLAS AND HIS SOCIOBIOLOGICAL INFORMATIONAL THEORY}

\begin{abstract}
The Informational Sociobiological Theory proposes a radically-different definition of living systems and, therefore, is the only existing neurological theory that evades the mind-brain problem and explains the nature of human consciousness. It was developed by Pedro Ortiz Cabanillas between 1984 and 2011. In this document we are presenting a listing of his main works. We include, additionally, unpublished material of the years 1998, 1999, 2006, and 2009.
\end{abstract}

Keywords: Information; General systems theory; Neocortex; Paleocortex; Society (source: MeSH NLM)

\section{INTRODUCCIÓN}

En el Perú, entre 1984 y 2011, se desarrolló la Teoría Sociobiológica Informacional (TSI). Este esfuerzo fue realizado por Pedro Ortiz Cabanillas (1933-2011) quien, a lo largo de estos años brindó un sinnúmero de clases y conferencias y al mismo tiempo escribió y publicó diversos artículos y libros. Ciertamente, a diez años de haber empezado, publicó su primer libro «El sistema de la personalidad» (1994) ${ }^{(1)}$ donde detalla los planteamientos de su teoría. Luego de este libro, desarrolla la TSI en diversos ámbitos, pero esencialmente en sus temas vocacionales: la medicina, la educación y la ética.

El objetivo del presente artículo es hacer un recorrido por toda la obra de Pedro Ortiz Cabanillas, a fin de que cualquiera pueda orientarse mejor en el mar de su presencia. Ciertamente, «aprender una teoría» no es lo mismo que «conocer las ideas». Pedro Ortiz Cabanillas no tiene sólo ideas (en realidad es lo que más tiene, pero no es lo importante en este caso), tiene algo más, algo arquitectónicamente significativo y trascendental: tiene una teoría. Digámoslo de este modo: como la «Teoría de la gravedad», «Teoría de la evolución», como la «Teoría del Big Bang», así, Pedro Ortiz Cabanillas elaboró la TSI. Con, obviamente, sus propias leyes (sus tesis fundamentales, que son cinco, por cierto). La trascendencia de este aporte desborda, sin duda, cualquier campo de trabajo o disciplina: práctica clínica, salud pública, medicina, antropología, sociología, filosofía, economía, etc. En este sentido no hay que preguntarnos qué aporta la TSI a tal o cual disciplina. Mejor hay que ser conscientes que tanto la TSI representa una explicación (radicalmente) original del

\footnotetext{
Grupo de Investigación GRINA. Universidad Privada Norbert Wiener. Lima, Perú.

Centro de Desarrollo Integral RINCONADA.

Grupo de Investigación NEURON, Universidad Nacional Mayor de San Marcos. Lima, Perú

Programa Nacional de Becas y Crédito Educativo, Ministerio de Educación. Lima, Perú.

Médico Cirujano. Neurólogo educativo. Magister en Epidemiología, Salud Pública, Gerencia Social y Gestión Publica; ${ }^{\text {b }}$ Licenciado en Psicología, Magister en Neurociencias aplicadas a la Educación; ${ }^{\circ}$ Estudiante de Medicina Humana.

Recibido: 30/08/2018 Aprobado: 28/11/2018 En línea: 21/12/2018
}

Citar como: Contreras-Pulache H, Espinoza-Lecca E, Sevillano-Jimenez J. Apuntes sobre la evolución histórica de la obra de Pedro Ortiz Cabanillas y su Teoría Sociobiológica Informacional. Rev Peru Med Exp Salud Publica. 2018;35(4):699-706. doi:10.17843/rpmesp.2018.354.3892. 
«mundo»: es menester, y labor aún pendiente, el pensar, o mejor: repensar (valga la redundancia: de nuevo, valga la especificidad: desde cero) todo lo que hacemos o sabemos en cualquier disciplina actualmente existente. En ese sentido, ¿es factible pensar una salud pública informacional? definitivamente sí, y aun cuando no es aquí el lugar en que ello tenga su inicio, hay que adelantar que es probable que esta «salud pública informacional» sea algo completamente nuevo y distinto, como ha sucedido varias veces en la historia de la sociedad, cada vez que ha ocurrido un logro científico.

Así, para orientar mejor a cualquier lector interesado, escribimos este artículo. Venimos revisando desde hace más de siete años (Ortiz falleció en marzo 2011) el «Archivo Pedro Ortiz Cabanillas». Esto lo hacemos como un encargo del propio Pedro Ortiz Cabanillas, quien en febrero del 2011 nos legó esta (tremenda) responsabilidad. Siempre, se ha contado con el apoyo incondicional y tutelar de la Dra. Luisa Sakamoto, viuda de Pedro Ortiz Cabanillas. En este sentido, vamos a seleccionar material inédito del «archivo» y los vamos a mostrar en este artículo por vez primera, junto con imágenes de sus principales obras (Anexos).

\section{PRINCIPIO DE LA TEORÍA SOCIOBIOLÓGICA INFORMACIONAL}

El primer lugar, tenemos evidencia (hasta el momento de escribir estas líneas) que Pedro Ortiz Cabanillas inició el desarrollo de su TSI con la publicación: «El rol de las neurociencias en la explicación de la actividad psíquica», que se encuentra en los Anales del VIII Congreso Nacional de Psiquiatría de 1984. Hasta el 2011, logró publicar varias decenas de artículos científicos. A toda esta «obra breve», el mismo lo llamó: «La Explicación Informacional» (una primera edición de esta obra se publicó el 2011, conteniendo sólo diez artículos) ${ }^{(2-4)}$. Ciertamente, Pedro Ortiz Cabanillas nunca tuvo el menor interés por la publicación indizada, por perseguir un «índice Scopus», por «publicar en inglés». Su interés fue otro y más concreto: desarrollar su TSI y ponerla al servicio de quien quiera aplicarla en la práctica cotidiana, ya sea como médico, como educador, como psicólogo, como antropólogo, como sociólogo, como filósofo, etc. Alguna vez, se le preguntó: ¿Por qué publica sus artículos en revistas universitarias, muchas veces de corto alcance?, a lo que contestó: Si buscamos publicar nuestros mejores artículos en las grandes revistas extranjeras entonces ¿Cuándo vamos a nosotros tener nuestras propias grandes revistas? De este modo, mucha (sino la totalidad) de su obra breve se encuentra en medios impresos fuera de circulación o de difícil (sino imposible) acceso, de ahí, que una labor recopilatoria tenga suma importancia editorial. Actualmente se tiene en prensa una edición integral cuyo contenido se muestra en la Tabla 1.

\section{LA TEORÍA SOCIOBIOLÓGICA INFORMACIONAL APLICADA A LA MEDICINA}

Diez años tuvieron que transcurrir para que Pedro Ortiz Cabanillas publicará su primer libro: «El sistema de la personalidad» (1). A partir de aquí empezó a desarrollar su proyecto médico central: explicar cómo realizar una entrevista clínica y cómo llevar adelante un examen clínico integral. Este proyecto le tomó casi 15 años y empezó a publicarse en 1996 «Introducción a la Medicina Clínica. El examen clínico esencial» ${ }^{(5)}$, se continuó en 1999 "Introducción a la Medicina Clínica 3. El examen neurológico integral» ${ }^{(6)}$, y se concluyó en 2006 (con una segunda edición para el 2009) con «Introducción a la Medicina Clínica 2. El examen psicológico integral» (7). Posterior a este año, Pedro Ortiz Cabanillas se dedicó a trabajar en un libro que dejaría inconcluso: «Neurociencia clínica. Una explicación de los trastornos, defectos y deterioros neuropsíquicos de la personalidad». En este libro, redefine el concepto de enfermedad y propone una explicación clínica de los problemas de la salud desde la TSI. El libro, luego de tres años de trabajo editorial (a cargo de los doctores Alberto Perales, Pablo Zumaeta, Romell Ibarra, y Hans Contreras-Pulache) está actualmente en prensa y se espera su pronta publicación.

\section{LA TEORÍA SOCIOBIOLÓGICA INFORMACIONAL APLICADA A LA EDUCACIÓN}

Cuando Pedro Ortiz Cabanillas publicó su teoría (1) en 1994, la recepción de la misma fue muy buena en los ámbitos educativos. Los educadores, más que los médicos, vieron en el planteamiento de la TSI un apoyo en la resolución de sus necesidades y demandas concretas. A pedido de un grupo de educadores, que le insistían que escribiera una «versión para educadores» de su TSI, Ortiz escribió y publicó en 1997: «La Formación del sistema de la Personalidad. Apuntes de interés pedagógico» (8). Esta obra es una síntesis de las ideas expuestas en 1994 pero aplicadas a la problemática educativa. La preocupación educativa persistió siempre, de ahí que más de diez años luego de haber publicado este libro, volvió a publicar uno mucho más elaborado y estructurado: «Educación y formación de la personalidad» (9) (2008). Para muchos, este libro constituye el modo más ideal de acercarse a leer y a comprender la TSI de Pedro Ortiz Cabanillas.

\section{EL DESARROLLO DE LA TEORÍA SOCIOBIOLÓGICA INFORMACIONAL}

En la década de los 90, Pedro Ortiz Cabanillas cesó sus funciones laborales en el sistema de salud. Había sido médico asistencial en el Seguro Social por varias décadas, 
Tabla 1. La Explicación Informacional (1984-2011)

\begin{tabular}{|c|c|c|}
\hline Año & Título & Publicado en: \\
\hline 1984 & $\begin{array}{l}\text { El rol de las Neurociencias en la explicación de la } \\
\text { actividad psíquica. }\end{array}$ & $\begin{array}{l}\text { Libro. Anales del VIII Congreso Nacional de Psiquiatría } \\
\text { Peruana }\end{array}$ \\
\hline 1988 & $\begin{array}{l}\text { Rol de los sistemas frontales en el procesamiento de la } \\
\text { información en el hombre. Aspectos psicofisiológicos. }\end{array}$ & $\begin{array}{l}\text { Libro. La Neuropsicología, una nueva rama en el } \\
\text { conocimiento psicológico. Tomo V. Universidad de la } \\
\text { Habana }\end{array}$ \\
\hline 1989 & ¿Tiene nuestro cerebro zonas sin funcionar? & SABER. Suplemento diario La Republica. \\
\hline 1991 & $\begin{array}{l}\text { El Problema de la Personalidad en Neuropsicología. } \\
\text { Problemas de Neuropsicología. }\end{array}$ & Revista del Grupo de Estudio y Trabajo Neuropsicológico \\
\hline 1992 & $\begin{array}{l}\text { Desórdenes de la Personalidad en las Lesiones } \\
\text { Cerebrales: Una Reinterpretación. }\end{array}$ & $\begin{array}{l}\text { Libro. Anales del XII Congreso Nacional de Psiquiatría } \\
\text { Peruana }\end{array}$ \\
\hline 1995 & Atención del Paciente con Dolor de Cabeza. & Revista Peruana de Neurología \\
\hline 1995 & Atención del Paciente con Mareos. & Revista Peruana de Neurología \\
\hline 1995 & La Afectividad Humana. & Revista Psiquiátrica Peruana \\
\hline 1996 & Atención del Paciente Confuso. & Revista Peruana de Neurología \\
\hline 1997 & El Componente Moral de la Personalidad. & Revista de Filosofía. Reflexión y Crítica. \\
\hline 1997 & Aspectos éticos de la decisión terapéutica. & Revista de Salud y Medicamentos \\
\hline 1997 & $\begin{array}{l}\text { Hacia una Psicofisiología de la Afectividad Humana y la } \\
\text { Motivación. }\end{array}$ & $\begin{array}{l}\text { Revista de Psicología. Facultad de Psicología de la } \\
\text { UNMSM. }\end{array}$ \\
\hline 1997 & Personalidad, Cerebro y Sociedad. & $\begin{array}{l}\text { Libro. Investigación en Psicología: Retos para el Futuro, } \\
\text { Resúmenes del Simposio del XX Aniversario del Instituto de } \\
\text { Investigaciones Psicológicas, UNMSM. }\end{array}$ \\
\hline 1997 & Un Concepto de Psiquismo. & Revista de Epistemología \\
\hline 1998 & Atención del Paciente con Crisis Epilépticas. & Revista Peruana de Neurología \\
\hline 1998 & $\begin{array}{l}\text { Los problemas de aprendizaje y la formación de la } \\
\text { personalidad. }\end{array}$ & Revista Archivos Peruanos de Psiquiatría y Salud Mental \\
\hline 1999 & Concepciones de la Inteligencia. & $\begin{array}{l}\text { Revista de Educación Superior, Facultad de Educación, } \\
\text { UNMSM. }\end{array}$ \\
\hline 1999 & Conciencia y Memoria. & $\begin{array}{l}\text { Libro. Ponencias del Forum Internacional de Educación } \\
\text { "Encinas 99", Lima }\end{array}$ \\
\hline 1999 & Estrés y Sufrimiento. & Revista de Investigación en Psicología \\
\hline 2000 & La formación de la personalidad. & Revista Ideele \\
\hline 2000 & $\begin{array}{l}\text { Los problemas morales de la educación médica en la } \\
\text { sociedad actual. }\end{array}$ & $\begin{array}{l}\text { Libro. Segundas Jornadas de Investigación en Salud, } \\
\text { UNMSM. }\end{array}$ \\
\hline 2000 & Naturaleza de la cognición humana. & Revista Peruana de Neurología \\
\hline 2000 & $\begin{array}{l}\text { El mercado profesional como determinante de inconducta } \\
\text { médica }\end{array}$ & Revista Anales de la Facultad de Medicina \\
\hline 2001 & Atención del paciente con demencia & Revista Peruana de Neurología \\
\hline 2001 & El lugar de la Bioética en la atención de salud. & $\begin{array}{l}\text { Situa, Revista de la Facultad de Medicina, Universidad } \\
\text { Nacional de San Antonio Abad de Cusco. }\end{array}$ \\
\hline 2001 & La Neuropsicología de Alexander Luria. & $\begin{array}{l}\text { Situa, Revista de la Facultad de Medicina, Universidad } \\
\text { Nacional de San Antonio Abad de Cusco. }\end{array}$ \\
\hline 2001 & Maduración cerebral y formación de la conciencia. & $\begin{array}{l}\text { Libro. Educación Peruana: Balance y Perspectivas. I Forum } \\
\text { Nacional Encinas-Vigotsky }\end{array}$ \\
\hline 2001 & $\begin{array}{l}\text { Necesidad de un Enfoque Ético de la Educación en } \\
\text { Medicina. }\end{array}$ & Revista Anales de la Facultad de Medicina \\
\hline 2001 & Una concepción de Intelecto e Inteligencia. & $\begin{array}{l}\text { Revista Educación, Facultad de Ciencias de la Educación, } \\
\text { UNIFE. }\end{array}$ \\
\hline 2002 & Aspectos neurológicos de la motivación y la voluntad. & Revista Peruana de Neurología \\
\hline 2002 & $\begin{array}{l}\text { La indicación de los exámenes instrumentales: un } \\
\text { problema moral. }\end{array}$ & Revista Médica \\
\hline
\end{tabular}

Fuente: Archivo Pedro Ortiz Cabanillas, elaboración propia 
Tabla 1. La Explicación Informacional (1984-2011) (continuación)

\begin{tabular}{|c|c|c|}
\hline Año & Título & Publicado en: \\
\hline 2004 & Cerebro y Moral & $\begin{array}{l}\text { Libro. Anales del XVIII Congreso Peruano de } \\
\text { Psiquiatría y III Reunión Regional Bolivariana de la } \\
\text { Asociación Psiquiátrica de América Latina. }\end{array}$ \\
\hline 2004 & Desarrollo formativo de la actividad psíquica personal. & Revista Paediatrica \\
\hline 2004 & El problema del sujeto de la educación. & $\begin{array}{l}\text { Revista Educación. Revista de la Facultad de } \\
\text { Educación, UNMSM. }\end{array}$ \\
\hline 2004 & El valor moral del tiempo. & Revista Anales de la Facultad de Medicina \\
\hline 2005 & ¿Se puede medir el aprendizaje de la ética médica? & Revista Anales de la Facultad de Medicina \\
\hline 2006 & Integración Neural de la Actividad Personal Femenina. & Libro. Ginecología y Obstetricia. Lima. \\
\hline 2007 & $\begin{array}{l}\text { Un replanteamiento del problema de la relación entre el sistema } \\
\text { educacional y el sujeto de la educación. }\end{array}$ & Revista Aristas \\
\hline 2008 & $\begin{array}{l}\text { Acerca del Código de Ética y Deontología del Colegio Médico } \\
\text { del Perú: Fundamentos teóricos. }\end{array}$ & Revista Acta Médica Peruana \\
\hline 2008 & Bases éticas de la formación profesional en Medicina. & $\begin{array}{l}\text { Revista Peruana de Medicina Experimental y Salud } \\
\text { Pública }\end{array}$ \\
\hline 2008 & $\begin{array}{l}\text { Estado de moralidad/inmoralidad de una escuela de medicina y un } \\
\text { hospital público: aplicación de una estrategia de moralización. }\end{array}$ & Revista Anales de la Facultad de Medicina \\
\hline 2008 & Inconsciencia y consciencia. & Revista Peruana de Neurociencias \\
\hline 2009 & Generación de conocimiento. & Anastomosis. Cuadernos de Medicina 2 \\
\hline 2009 & Código de Ética y Deontología & Libro. VIII Congreso Médico Nacional, Lima. \\
\hline 2010 & Bases Científicas de la educación. & $\begin{array}{l}\text { Libro. Pedagogía Crítica. Instituto de Pedagogía } \\
\text { Popular - IPP, Lima. }\end{array}$ \\
\hline 2010 & Bajo el cielo de Lima. Entrevista. & Anastomosis. Cuadernos de Medicina 3 \\
\hline 2010 & ¿Qué es la música? & Anastomosis. Cuadernos de Medicina 3 \\
\hline 2011 & El punto de vista social de la Neurociencia. & Libro. La explicación informacional. Tomo 3 \\
\hline
\end{tabular}

Fuente: Archivo Pedro Ortiz Cabanillas, elaboración propia

desempeñando por mucho tiempo la dirección del servicio de Neurología y Neurocirugía del Hospital Edgardo Rebagliati Martins. Aquí, se recuerda que en las discusiones de casos clínicos: «luego que hablaba Pedro Ortiz, ya no había nada más que decir», tal era su maestría clínica. Desde 1992, ya no trabajó en el sistema asistencial, y esencialmente se dedicó a desarrollar la TSI y a aplicarla. En 1994 publicó su primer libro ${ }^{(1)}$, y su siguiente salto fue en 1998 cuando publicó «El nivel consciente de la memoria. Una hipótesis de trabajo» ${ }^{(10)}$. Aquí, desarrolló una explicación de la naturaleza del hipocampo. Al mismo tiempo, en este libro se deja de modo explicito la visión tan distinta que tenía del sistema nervioso humano. Por ejemplo, en la Neurociencia o la Neurología tradicional, el sistema nervioso se estudia como sistema nervioso central y sistema nervioso periférico, para Pedro Ortiz esta diferencia no tiene la menor importancia. En la forma tradicional de entender al sistema nervioso se considera que el cerebro está constituido por lóbulos, y que los fenómenos psicológicos se encuentran distribuidos «de algún modo» a lo largo de dichos lóbulos, o resultan de la supuesta unión articulada de estos. Para Ortiz, en el cerebro no existen lóbulos y no es que lo psicológico se encuentre en el cerebro, sino que el cerebro es psicológico en su totalidad. En este libro, llega incluso a proponer cuál es la «función» del hipocampo y a contracorriente de todos los planteamientos contemporáneos, afirma que el hipocampo no es de naturaleza psíquica sino informacionalmente supranuclear. A diferencia del libro de $1994{ }^{(1)}$, donde expuso sintéticamente toda su obra, es en la publicación de 1998 donde sustentó con maestría su explicación radicalmente original del sistema nervioso humano.

Para finales de la década de los 90 tenemos a un Pedro Ortiz Cabanillas dueño de un modo único de pensar acerca de la naturaleza humana. Dos brevísimos textos inéditos de esta época nos van a permitir dejar constancia de este hecho (Tabla 2).

Con todo esto, y el ingreso al nuevo milenio, Pedro Ortiz Cabanillas emprendió uno de sus más grandes proyectos. Desarrollar una explicación de la naturaleza humana desde la TSI. Seguro que este sería un trabajo de largo aliento, se dispuso a imaginar toda su explicación a lo largo de varios «Cuadernos de Psicobiología Social» (11,12). El contexto en el cual se empezó a desarrollar esta obra fue cuando tuvo la oportunidad de hacerse cargo de la cátedra de Psicobiología Social de la facultad de Psicología de la Universidad de Lima, y luego cuando organizó las cátedras de la maestría 
Tabla 2. Dos textos inéditos $(1998,1999)$

\section{LA LIBERTAD: ASPIRACIÓN SUPREMA DEL HOMBRE (1998)}

Entre los valores a los cuales ha aspirado y seguirá aspirando la humanidad se encuentran los de libertad, justicia, paz. Los hombres esperarían desarrollarse íntegramente como tales si es que se lograra hacer realidad siquiera uno de ellos: entonces los otros, y otros más, se alcanzarían por su propio peso. Hasta la bondad y la belleza se podrían conseguir si es que hubiera libertad, por ejemplo.

Sin embargo, un problema real para los hombres reales es que es muy difícil conseguir algo que se plantea sólo en términos abstractos. Así un niño no tendrá la convicción del valor del trabajo con sólo saber que el pan es bueno para saciar el hambre. Él tiene que tener un pan y comerlo para sentir la satisfacción de ser fuerte y capaz de trabajar para conseguirlo.

Hablar de la libertad en abstracto, dificulta, entonces, la posibilidad de llegar a ser libre. Y es que, en realidad, La Libertad como abstracción, por más mayúsculas que le pongamos, no se come, como decía alguien de mente muy estrecha pero pragmática.

Por eso, para facilitar la comprensión de entes abstractos como éste, por lo general se vale uno de analogías; así, se nos dice que debemos ser libres como las aves. Aunque parezca mentira, esta analogía se usa frecuentemente en las ciencias para explicar, por ejemplo, la naturaleza humana. Por eso sabemos a ciencia cierta que somos animales superiores, y por tanto tan libres como todos ellos.

Pero creo que ésta es una falacia irreverente. En efecto, hace unos 7 mil años que dejamos de ser animales superiores, porque de la especie Homo sapiens surgió la sociedad humana. Desde entonces hemos dejado de ser libres como los animales.

Desde entonces existe la información social que debemos incorporar desde que nacemos para así tener una conciencia. Desde entonces, ser libre significa tener la mayor cantidad posible de información social, y de la mejor calidad, en el cerebro. Por eso la libertad animal que traemos al momento de nacer, debe dar paso a la libertad personal, consciente que, desafortunadamente, depende de las condiciones sociales en que cada personalidad se forma y desarrolla. Si una sociedad garantiza que cada persona acumule la mayor cantidad de sentimientos, conocimientos y convicciones espirituales que hacen posible el bienestar humano, sólo entonces la calificaremos de justa y solidaria. De lo contrario, será solamente liberal.

\section{EL CEREBRO HUMANO (1999)}

Cuando en el colegio estudiamos el cerebro, seguramente que ni el profesor ni el alumno se percatan de que la teoría no hace mayor distingo entre el cerebro de los monos, por ejemplo, y el de los hombres. Todos, por desgracia, seguimos la idea de Darwin de que los hombres pertenecemos a la especie Homo sapiens, y que por lo mismo nuestros cerebros no difieren mayormente en cuanto a su anatomía y función, aunque también respecto de la actividad psíquica. Por eso se cree que el cerebro humano tiene sólo dos componentes, uno emocional y otro cognitivo.

Cuando formulamos nuestra teoría acerca del sistema de la personalidad, sin embargo, nos ha sorprendido poder comprobar que el cerebro de las personas ya tiene una organización muy diferente a la de los animales, inclusive de los llamados superiores. En efecto, hemos sustentado un modelo del cerebro humano que muestra que éste tiene esencialmente dos niveles de organización de índole psíquica: uno inconsciente y otro consciente. Aunque en este caso usamos el término inconsciente tomado de Freud, no nos estamos refiriendo a impulsos, instintos o algo parecido, sino a las sensaciones afectivas (olor, sabor, frío, miedo, cólera) y a las sensaciones cognitivas (tactiles, visuales, auditivas) que ocupan regiones especiales de la corteza cerebral que se conocen como alocórtex. El otro nivel de organización, a diferencia del anterior que compartimos con los animales, ya es exclusiva y eminentemente humano: comprende una zona mucho más extensa de la corteza cerebral que es el neocórtex, el cual es, en realidad, un sistema de memoria que guarda información de origen social en la forma de información psíquica consciente, como son los sentimientos, los conocimientos y las motivaciones que nos caracterizan. $Y$ es el conjunto de todas estas clases de información que logramos acumular en nuestro cerebro lo que constituye nuestra conciencia. $Y$ la conciencia es lo único que convierte a cada ser humano en una personalidad.

Fuente: Archivo Pedro Ortiz Cabanillas, elaboración propia

y del doctorado de Neurociencias en la Universidad Nacional Mayor de San Marcos. Para todo esto, Pedro Ortiz Cabanillas empezó a trabajar de modo simultáneo en siete cuadernos distintos. Cada uno de estos cuadernos daría cuenta de un nivel de organización informacional del ser humano. El cuaderno 1 se titula «Introducción a una Psicobiología del Hombre» (11), y le siguen el cuaderno 2 «El nivel celular de la actividad personal», el cuaderno 3 «El nivel metabólico de la actividad personal», el Cuaderno 4
«El nivel funcional de la actividad personal», el cuaderno 5 «EI nivel inconsciente de la actividad personal», el cuaderno 6 «El nivel consciente de la actividad personal» ${ }^{(12)}$, y el cuaderno 7 «El desarrollo de la actividad psíquica personal». En el 2004, Pedro Ortiz Cabanillas pudo terminar y publicar sólo el cuaderno 1 y el cuaderno $6^{(12)}$ (el 2010 publicó una segunda versión del cuaderno 1). Estos siete cuadernos de la Psicobiología Social se elaboraron a lo largo de toda la década del 2000-2010. Recientemente, y luego de un arduo 
trabajo editorial, se ha logrado publicar la totalidad de estos siete cuadernos en una obra de tres tomos, con el título de «Psicobiología Social» ${ }^{(13-15)}$.

Mientras trabajaba en sus cuadernos ${ }^{(11,12)}$, y luego de haber revolucionado a toda la Neurología contemporánea, emprendió un trabajo que se daría a conocer el 2002 «Lenguaje y habla personal. El cerebro humano como sistema semiótico» (16). En esta obra, expuso la explicación del lenguaje desde la perspectiva de la TSI. Propuso aquí la existencia de la preconsciencia, que son las áreas corticales de transición (de ambos hemisferios), y al mismo tiempo, en contra de lo que se cree habitualmente, para Pedro Ortiz la preconsciencia se asienta en ambos hemisferios cerebrales (mucho de la neurociencia y neurología tradicional propone que el lenguaje se asienta sólo en el hemisferio izquierdo del cerebro). Para el 2008, tenía una segunda edición de este libro, que no llegó a publicar, y que tituló «El nivel preconsciente de la actividad personal».

El 2007 publicó su libro: «Ética social. Para el desarrollo moral de las instituciones educacionales y de salud» (22), que según sus palabras era una suerte de «manifiesto». El 2008 publicó su libro «Educación y formación de la personalidad» (9). Entre el 2009 y 2011, trabajó esencialmente en su libro "Neurociencia clínica» (que no llegó a concluir), y en diversos textos breves que terminó y que permanecen inéditos (estos textos constituyen el cuerpo no publicado de «La Explicación Informacional»). La Tabla 3 muestra, complementando la Tabla 2, uno de estos textos inéditos.

Para finales del 2010, escribió un artículo sintetizando toda su obra (el texto se titula: «La Teoría Sociobiológica de Pedro Ortiz Cabanillas» y se incluyó como un anexo en la segunda edición de «El sistema de la Personalidad») (23). En este artículo manifestó que la TSI consta de cinco leyes fundamentales que, como herramientas teóricas puede sostener una forma radicalmente distinta de explicar el desarrollo de los sistemas vivos (fundamenta una forma de definir la vida y construye una sistemática informacional) y el desarrollo de la historia (y lo más particular es que esto último, lo hace desde una visión informacional del sistema nervioso y de la sociedad).

\section{LA VOCACIÓN DE MAESTRO}

En la vida de Pedro Ortiz Cabanillas, siempre se resalta su presencia en términos de posicionarlo en un contexto de enseñanza permanente, demostrando en toda ocasión la misma y absoluta dedicación. Un día podía encontrársele preparando una presentación para un curso de doctorado y otro día preparando una exposición para estudiantes de secundaria de un colegio que lo había invitado a dar una conferencia. Pedro Ortiz Cabanillas gozaba de ese don, contaba con todos los elementos para motivar el desarrollo de una capacidad de pensamiento original y crítico (17-21), siempre predispuesto a conversar, a dialogar y a enseñar. Vamos a relatar el siguiente episodio biográfico para dejar constancia de esto. En 2006, a sus 75 años, recibió una carta de un grupo de estudiantes de Psicología, que en Arequipa venían trabajando con su obra desde 1995, y con quienes se había reunido periódicamente para orientarlos en sus planteamientos. Vamos a transcribir algunos fragmentos de esta carta y algunas respuestas de Pedro Ortiz Cabanillas para dejar en evidencia la calidad del trato y disposición que tuvo siempre con sus estudiantes.

La carta está estructurada en tres partes. En una primera parte se presenta el grupo de estudiantes:

Doctor Pedro Ortiz Cabanillas.

A nombre del «Grupo de estudios psicológicos $\mathrm{H}$. Wallon» de la ciudad de Arequipa, nos permitimos dirigirnos a Ud. por este medio para primero saludarlo muy afectuosamente y transmitirle también nuestra profunda admiración por su grandiosa obra y aporte a las ciencias humanas en general y a la Psicología en particular. En segundo término, manifestarle que como seguidores de sus planteamientos y teniendo nosotros un conjunto de inquietudes sobre los mismos, no tenemos otra forma que ésta para transmitírselas, con la esperanza de que, robándole unos minutos de su valioso tiempo, pueda enviarnos sus respuestas y su apoyo. Agradeciéndole desde ya la atención que le pueda merecer esta comunicación, queremos de manera muy sintética y a manera de presentación, referile nuestros antecedentes como grupo de estudios:

(...)

2) De sus planteamientos tomamos conocimiento el año 1995 aproximadamente al leer su obra: «El sistema de la Personalidad».

Desde entonces hasta hoy no nos hemos detenido en el estudio de sus aportes.

(...)

Una segunda parte donde se le hacen 14 preguntas sobre cuestiones generales, resalta la primera y las dos últimas:
1. ¿Cómo define Ud. a la ciencia?
(...)
13. En la entrevista que le hicimos en 1997 Ud. nos comunicó que en Inglaterra tuvo como maestro a un discípulo de Vigotsky, ¿cuál era su nombre?
14. Disculpe el atrevimiento, desearíamos saber la fecha de su nacimiento completo y en que tema está Ud. trabajando ahora. (...)

En la tercera parte donde se hacen seis preguntas sobre los planteamientos específicos de la Teoría (con respecto a su planteamiento teórico).

La respuesta (cuya extensión es de unas diez páginas), empieza así:

Queridos amigos, Giovanna, Ronal y miembros del «Grupo de Estudios Psicológicos Henri Wallon» 
Tabla 3. Texto inédito (2009)

\section{LOS PROBLEMAS DE SEARLE Y EL PROBLEMA DE LA CONCIENCIA}

The neurosciences have advanced to the point that we can now treat consciousness as a scientific problem like any other. The problem is to explain how brain processes cause consciousness and how consciousness is realized in the brain. Progress is impeded by a number of philosophical mistakes, and the aim of this paper is to remove nine of those mistakes:

(i) Consciousness cannot be defined;

(ii) Consciousness is subjective but science is objective;

(iii) Brain processes cannot explain consciousness;

(iv) The problem of 'qualia' should be set aside;

(v) Consciousness is epiphenomenal;

(vi) Consciousness has no evolutionary function;

(vii) A causal account of consciousness is necessarily dualistic;

(viii) Science is reductionistic, so a scientific account of consciousness would show it reducible to something else; and

(ix) An account of consciousness must be an information processing account.

Searle, J.P. How to study consciousness scientifically. Phil. Trans. R. Soc. Lond. B (1998) 353, 1935-1942*

Nuestra teoría de la conciencia, por el contrario, se ha fundamentado en los puntos siguientes:

i. La conciencia si puede definirse, siempre y cuando no se la defina en términos de un relación individuo-ambiente, sino como sistema de relaciones que refleja a la sociedad definida, a su vez, como estructura supraindividual organizada a base de información social

ii. La conciencia es, efectivamente, una actividad cerebral subjetiva: por lo tanto, puede ser explicada por una ciencia social integrada como ciencia de lo objetivo y lo subjetivo, es decir, como una ciencia que incluye, además de una explicación social del hombre, una explicación natural del desarrollo del mismo

iii. La teoría del cerebro sí explica la conciencia en sentido epigenético; así como la sociedad la explica en sentido sociocinético

iv. De acuerdo; los «qualia» no tienen lugar en una teoría científica social de la sociedad, la conciencia y la personalidad

v. Conciencia no es un fenómeno ni un epifenómeno: es simplemente el neocórtex de todo cerebro personal, una vez que ha sido estructurado al codificar la mencionada información social

vi. La conciencia sí puede determinar cambios evolutivos en sentido cinético (aunque no tiene función evolutiva)

vii. Una definición de la naturaleza genética y social de la conciencia, supera a las concepciones dualistas acerca de la misma

viii. Una explicación científica social integrada no es reduccionista

ix. Sí, pero en el sentido de que la explicación de la conciencia requiere de una explicación del sistema vivo como sistema informacional.

Fuente: Archivo Pedro Ortiz Cabanillas.

* Traducimos este texto en el que J. Searle plantea (en la introducción a su artículo: "How to study consciousness scientifically"):

Las neurociencias han avanzado hasta el punto en que actualmente podemos dar un tratamiento científico al problema de la consciencia. El problema está en explicar cómo el procesamiento cerebral causa la consciencia y cómo esta consciencia se realiza en el cerebro. El progreso es impedido por una serie de confusiones filosóficas, y el objetivo de este trabajo es remover nueve de estas equivocaciones.

(i) La consciencia no puede ser definida.

(ii) La consciencia es subjetiva mientras que la ciencia es objetiva.

(iii) El procesamiento cerebral no puede explicar la consciencia.

(iv) El tema de los "qualia" debería ser dejado de lado.

(v) La consciencia es un epifenómeno.

(vi) La consciencia no tiene una función evolutiva.

(vii) Toda explicación de la consciencia debe ser necesariamente dualista.

(viii) La ciencia es reduccionista, por tanto un científico interesado en la consciencia la reducirá inevitablemente en algo más, y

(ix) Una explicación de la consciencia debería contemplar una explicación del procesamiento de información.

Sesudas preguntas exigen exprimirse hasta el bulbo raquídeo. Antes que nada, mi reconocimiento y gratitud por el trabajo que están desarrollando.

\section{a) Respuestas generales:}

1. La ciencia, para mí, tiene que definirse en términos informacionales. A partir de los conceptos esbozados en mi cuaderno de Psicobiología 1, la defino como todo el conjunto de la información social de tipo cultural, que la sociedad ha acumulado, confrontado, a fin de describir, explicar los procesos que determinan la realidad actual, objetiva, del universo, a fin de transformarlo en su propio beneficio. (...)

13. No, no es así. Estuve en el servicio de afasiología y terapia del habla que dirigía la Dra. Joyce Mitchell (que me regaló un libro sobre mecanismos cerebrales del habla y el lenguaje que se le había caído al agua), quien hizo una estadía en el Instituto de Neurocirugía de Moscú, al lado de Luria.

14. Ahora estoy trabajando en la redacción de los Cuadernos de Psicobiología Social (2, 3, 4, 5), un libro sobre Neuropsicología Clínica (todavía sin nombre) y otro sobre Ética Social. Este último es una especie de manifiesto que saldrá, espero, el próximo mes. Acaba de salir Introducción a la Medicina Clínica II: El Examen Psicológico Integral (sus coautores son: César Sarria, Santiago Paredes y Rosa Ortiz). El o mi problema es que estoy en otras cosas administrativas que no he podido eludirlas: Dirijo el Instituto de Ética en Salud de la Universidad, presido la comisión organizadora de las celebraciones por el sesquicentenario de la fundación de la facultad de medicina, estoy representando a San Marcos en la Red de Macrouniversidades Públicas de América Latina y el Caribe, en el área de neurociencias 
(llevé a la Reunión de México un proyecto para investigar cómo los profesionales del área, integran neurociencia y ética en su práctica con pacientes); coordino el Doctorado en Neurociencias, y de "yapa» sigo dictando clases en pregrado y en otras maestrías y doctorados. Les estoy rogando a mis discípulos que se gradúen cuanto antes, para que me reemplacen, pero todavía sigo esperando. Mi cumpleaños es el 31-07.

(...)

\section{CONCLUSIONES}

A Pedro Ortiz Cabanillas sólo se le puede reprochar el haberse atrevido a vivir de un modo en que los hombres de su siglo no entenderían jamás por ser demasiado original, único y tal como él decía: «desde mi particular punto de vista...». Es imposible no verlo siempre resplandeciente, para quienes tuvimos el goce de conocerlo, de verlo enseñar, con esa pasión constante y ese convencimiento supremo de las cosas y de los hechos. Se cuenta que una vez, intrigado, en sus últimos tiempos, preguntó a su acompañante porqué todos lo trataban siempre de «Doctor». Si bajaba de un taxi, el chofer se despedía con un «Gracias, doctor»; si alguien lo atendía en un restaurante "Y usted, doctor, ¿qué va a ordenar...?». Ni el taxista ni el asistente del restaurante sabían que el era médico, doctor, y eso le intrigaba, ¿Por qué siempre se referían a el así? y la persona que lo acompañaba, no hizo más que sonreír, y decirle (tocándole el brazo) «es que irradias eso».

Actualmente, cuando se cuenta la historia de la Neurología en el Perú (24-26), se reconocen los aportes precolombinos y la presencia de ciertas figuras importantes de la primera mitad del siglo XX. Sin restarle mérito a esta etapa de la historia, y para complementar estos estudios históricos, nos vemos en la obligación de decir que fue en la segunda mitad del siglo XX en donde la obra de Pedro Ortiz Cabanillas se erige como el ejercicio intelectual más coherente y original que ha ofrecido el Perú a toda la historia de la Neurología universal y es, una responsabilidad darla a conocer, y sobre todo, como hubiera querido el maestro: continuar desarrollándola y aplicándola.

Contribuciones de los autores: EEL, HLCP y JASJ han participado en la concepción del artículo, la recolección de datos, redacción del artículo y aprobación de la versión final. Además, Hans Lenin Contreras Pulache realizo la revisión crítica del artículo.

\section{Fuentes de financiamiento: Autofinanciado}

Conflictos de interés: Hans Contreras Pulache es responsable académico del cuidado y publicación de la obra de Pedro Ortiz Cabanillas

\section{REFERENCIAS BIBLIOGRÁFICAS}

1. Ortiz P. El Sistema de la Personalidad. 1ed. Lima: Orión.1994

2. Ortiz P. La explicación Informacional (tomo 1). 1ed. Contreras-Pulache H, editor Lima (PE): Centro de Investigación Anastomosis; 2011.

3. Ortiz P. La explicación Informacional (tomo 2). 1ed. Contreras-Pulache H, editor. Lima (PE): Centro de Investigación Anastomosis; 2011 .

4. Ortiz P. La explicación Informacional (tomo 3). 1ed. Contreras-Pulache H, editor. Lima (PE): Centro de Investigación Anastomosis; 2011.

5. Ortiz P. Introducción a la Medicina Clínica. El examen clínico esencial. led. Lima: Fondo Editorial de la Universidad Nacional Mayor de San Marcos; 1996.

6. Ortiz P. Introducción a la Medicina clínica 3. El examen neurológico integral. 1ed. Lima: Fondo Editorial de la Universidad Nacional Mayor de San Marcos;1999.

7. Ortiz P. Introducción a la Medicina Clínica 2. El examen psicológico integral. 1ed. Lima: Fondo Editorial de la Universidad Nacional Mayor de San Marcos; 2006.

8. Ortiz P. La formación del sistema de la Personalidad. Apuntes de interés pedagógico. 1ed. Lima: Dimaso Editores; 1997.

9. Ortiz P. Educación y formación de la personalidad. 1ed. Lima: Fondo Editorial de la Universidad de Ciencias y Humanidades; 2008.

10. Ortiz P. El nivel consciente de la memoria: Una hipótesis de trabajo. 1ed. Lima: Fondo Editorial de la Universidad de Lima; 1998.
11. Ortiz P. Cuadernos de Psicobiología Social 1. Introducción a una Psicobiología del Hombre. 1ed. Lima: Fondo Editorial Universidad Nacional Mayor de San Marcos; 2004.

12. Ortiz P. Cuadernos de Psicobiología Social 6. El nivel consciente de la actividad personal. 1ed. Lima: Fondo Editorial de la Universidad Nacional Mayor de San Marcos; 2004.

13. Ortiz P. Psicobiología Social (tomo 1) led. Contreras-Pulache $\mathrm{H}$, editor. Lima (PE): Fondo Editorial de la Universidad de Ciencias y Humanidades; 2017.

14. Ortiz P. Psicobiología Social (tomo 2). 1ed. Contreras-Pulache $\mathrm{H}$, editor. Lima (PE): Fondo Editorial de la Universidad de Ciencias y Humanidades; 2017.

15. Ortiz P. Psicobiología Social (tomo 3) led. Contreras-Pulache $\mathrm{H}$, editor. Lima (PE): Fondo Editorial de la Universidad de Ciencias y Humanidades; 2017.

16. Ortiz P. Lenguaje y habla personal. El cerebro humano como sistema semiótico. led. Lima: Fondo Editorial Universidad Nacional Mayor de San Marcos. 2002.

17. Llontop D. Fuentes del pensamiento dialéctico en la teoría de la personalidad de Pedro Ortiz Cabanillas. Tesis para optar el grado de magister en Filosofia. 1ed. Lima: Universidad Nacional Mayor de San Marcos; 2007.

18. Perales-Cabrera A. Dr. Pedro Ortiz Cabanillas. Acta Méd Peru. 2011; 28(1):56-57.
19. Perales-Cabrera A. Testimonio: Pedro Ortiz Cabanillas(1933-2011). An Fac Med. 2011;72(1):83-87.

20. Zumaeta P. El Amauta Pedro Ortiz Cabanillas(1933-2011). Rev Peru Med Exp Salud Publica. 2011;28(4): 682-4.

21. Chero P. Pedro Ortiz, una visión personal. Rev Peru Epidemiol. 2011;15(1):75-6.

22. Ortiz P. Ética social. Para el desarrollo moral de las instituciones educacionales y de salud. 1ed. Lima: Fondo Editorial de la de la Universidad Nacional Mayor de San Marcos; 2007.

23. Ortiz P. El Sistema de la Personalidad. 2ed. Contreras-Pulache $\mathrm{H}$, editor. Lima (PE): Fondo Editorial de la Universidad de Ciencias y Humanidades; 2016.

24. Allegri R. The pioneers of clinical neurology in South America. J Neurol Sci. 2008;271(1-2):29-33.

25. Allegri R, Batoloni L. The first steps of clinical neurology in South America. Neurology. 2013;80(14):1338-40.

26. Arnott R, Finger S, Smith C, editors. Trepanation. 1ed. New York: CRC Press; 2003.

Correspondencia: Javier Alexander Sevillano Jimenez

Dirección: Av. del Pacifico 175 Torre E19 Dpto 902 Conj. Res. Parques de la Huaca-San Miguel. Lima, Perú.

Teléfono: (511) 983404109

Correo electrónico:javier-alexander_123@hotmail.com 
ANEXOS. A continuación, presentamos las imágenes de todos los libros que Pedro Ortiz Cabanillas publicó entre 1994 y el 2011 y los que han sido publicados de modo póstumo

Anexo 1. El primer libro de Pedro Ortiz Cabanillas. En el año 1994, Pedro Ortiz Cabanillas tenía 61 años cuando publicó su primer libro (A). Llevaba ya una década esbozando, lo que muchos años después llamaría: «La Teoría Sociobiológica Informacional de Pedro Ortiz». La segunda edición (B) se publicó el 2016, conteniendo una serie de anexos inéditos.

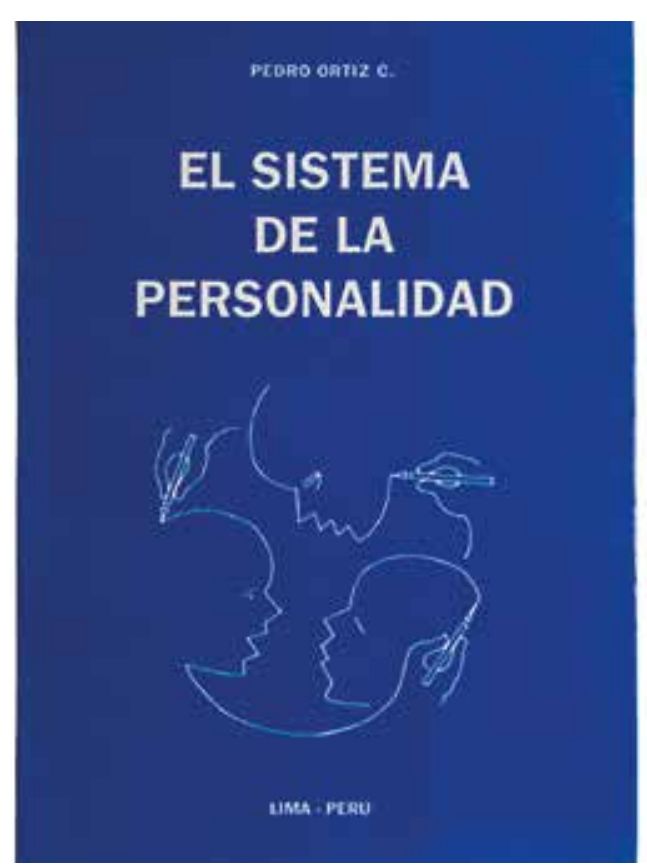

A

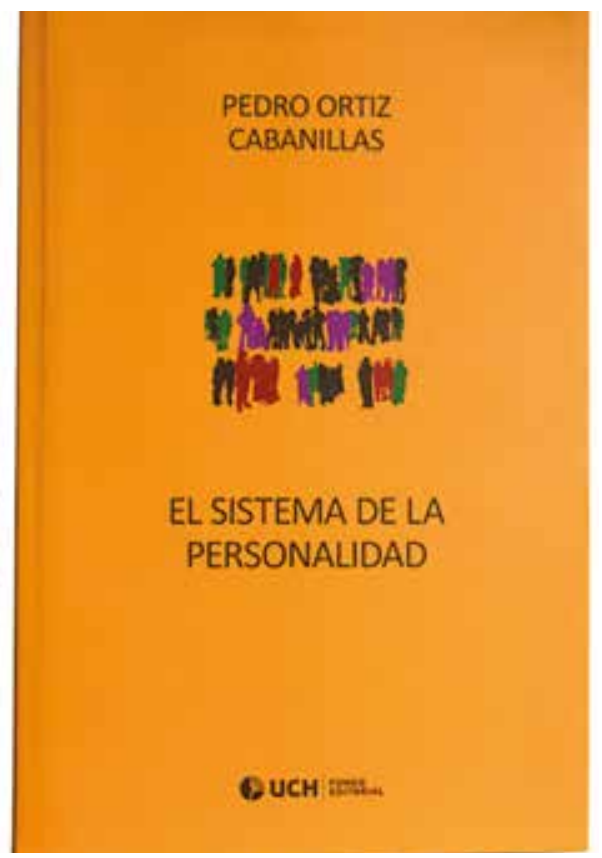

B 
Anexo 2. Los tres tomos de su obra «Introducción a la Medicina Clínica» donde se propuso fundar un método para realizar una «biografía clínica»

A

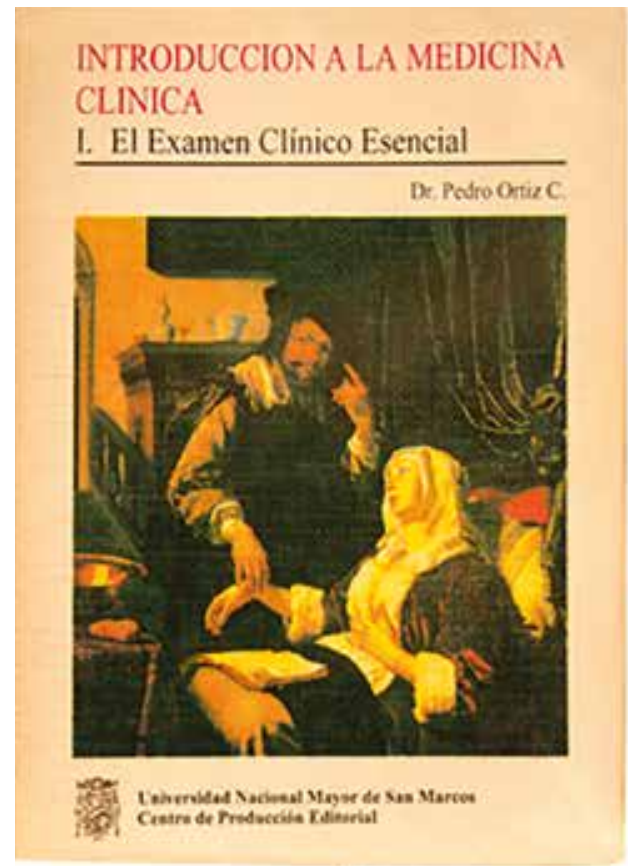

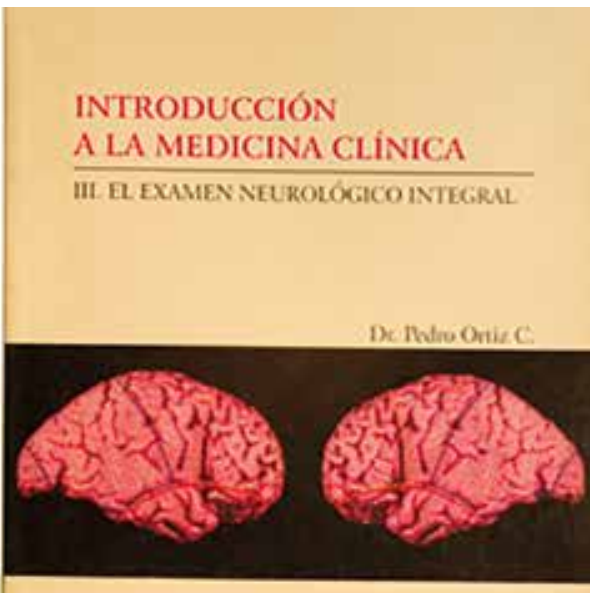

B

INTRODUCCIÓN
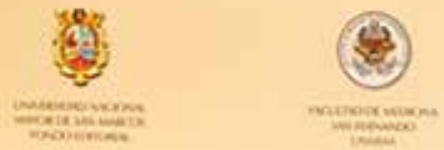

\section{A LA MEDICINA CLINICA}

II. EL EXAMEN PSICOLOGICO INTEGRAL

MasmuLionos

De. Pedro Ortix C.

C

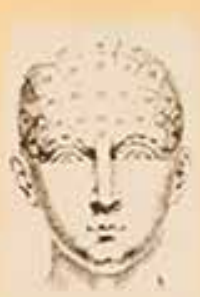

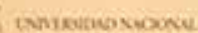


Anexo 3. En vano este libro no lleva por título «hipótesis de trabajo». Aquí, Pedro Ortiz Cabanillas muestra una visión profundamente particular de explicar al sistema nervioso humano. Propone que en el hipocampo no existe actividad psíquica sino funcional, supranuclear. Se expresa, plenamente, con términos que solo se pueden entender dentro del marco de la Teoría Sociobiológica Informacional.

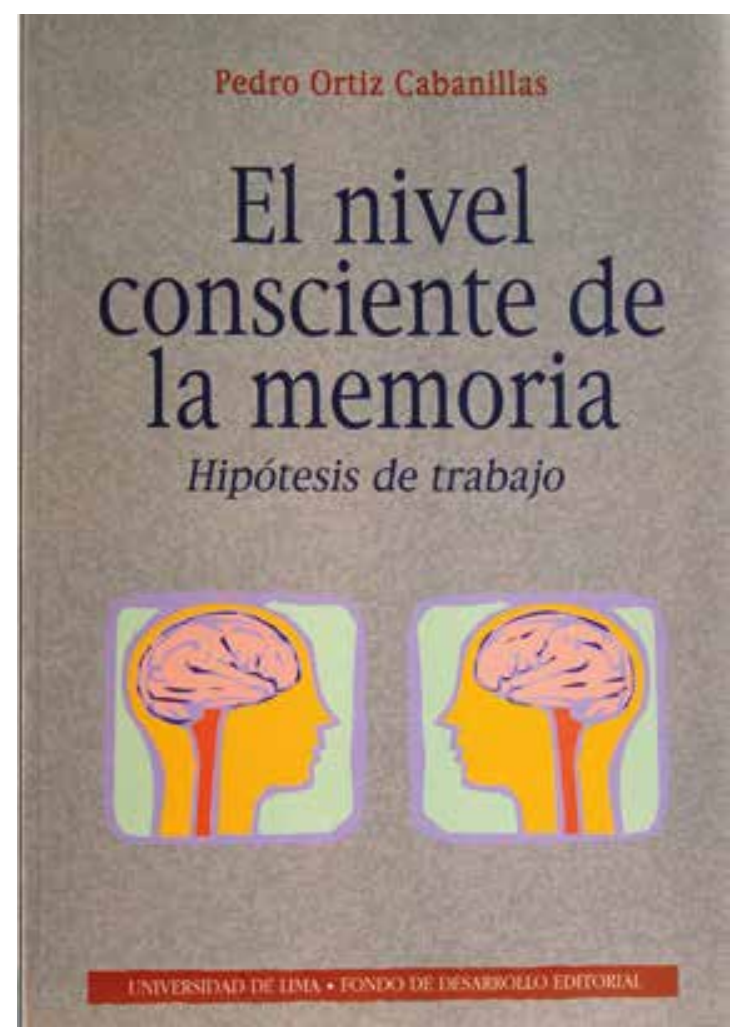


Figura 4. El libro (A) (1997) más leído, más publicado y más copiado. Se trata del primer libro de Neurología (o Neurociencias) para educadores escrito en el Perú. Probablemente el libro ideal (B) (2008) para aprender la Teoría Sociobiológica Informacional de Pedro Ortiz Cabanillas.

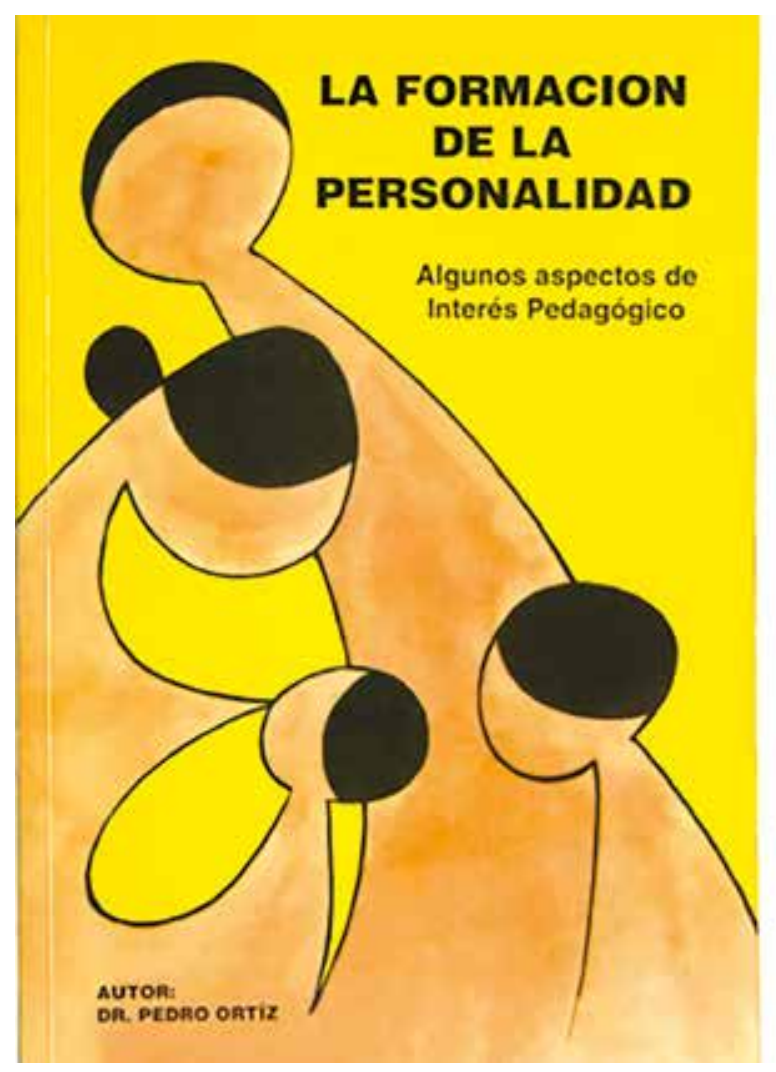

A

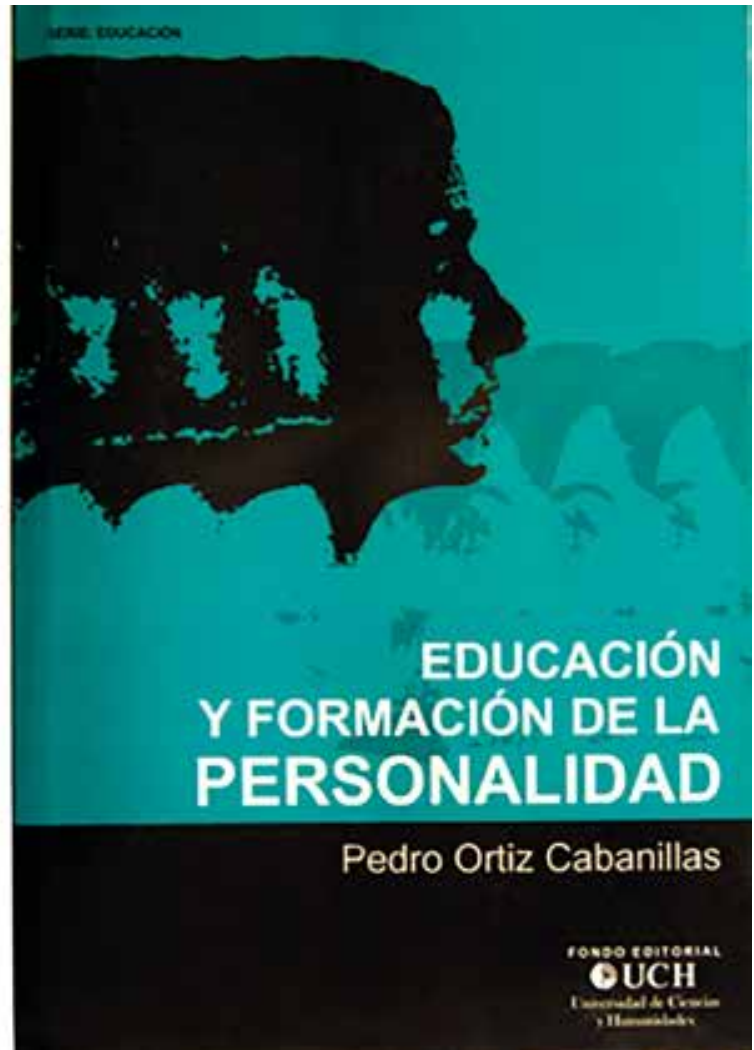

B 
Anexo 5. Una visión distinta del lenguaje. En este libro (2002), Pedro Ortiz Cabanillas elabora una visión neurológica del lenguaje. Es probablemente uno de sus libros más polémicos, dada la envergadura de sus críticas y planteamientos. Aquí sustenta la existencia de la preconsciencia, y elabora una reinterpretación de los llamados «problemas del lenguaje». Existe una segunda edición, concluida, e inédita

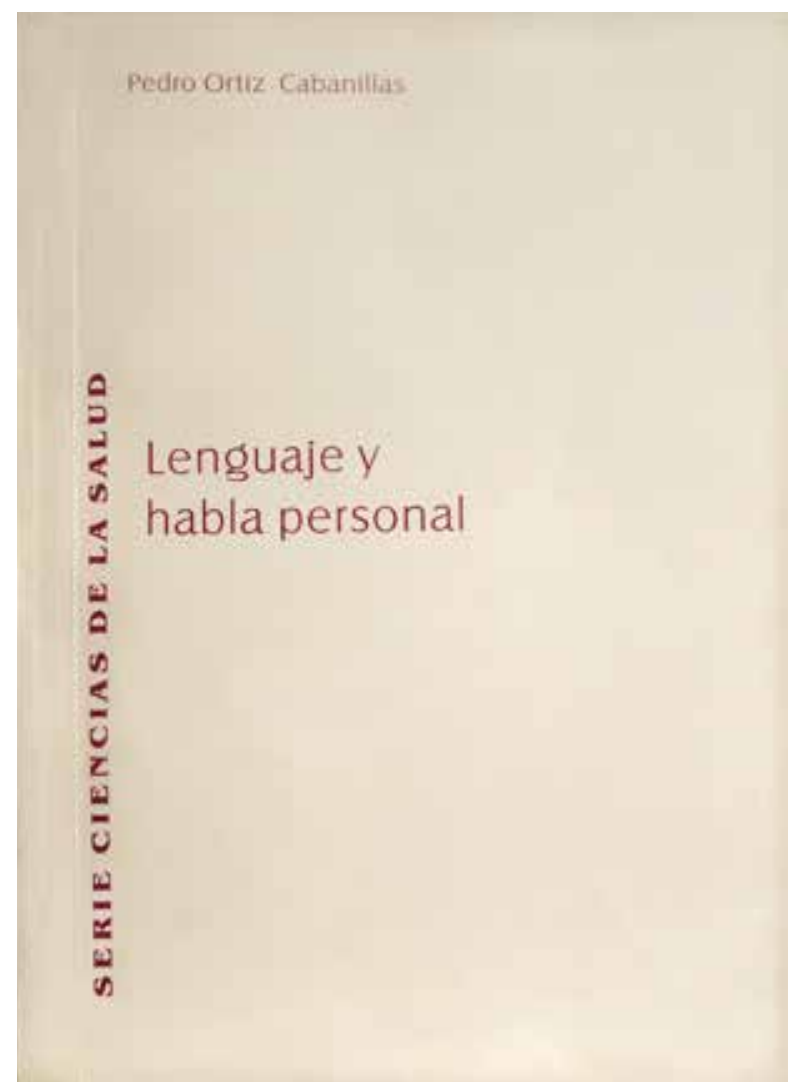


Anexo 6. De los siete «cuadernos» en los que Pedro Ortiz Cabanillas explica su visión del ser humano: abarcando desde su naturaleza celular hasta el desarrollo de su conciencia a lo largo de la vida, en vida, solo publicó: cuaderno 1 (A) (2004), cuaderno 6 (B) (2004) y, cinco años después, la segunda edición (ampliada) del cuaderno 1 (C) (2009)

A

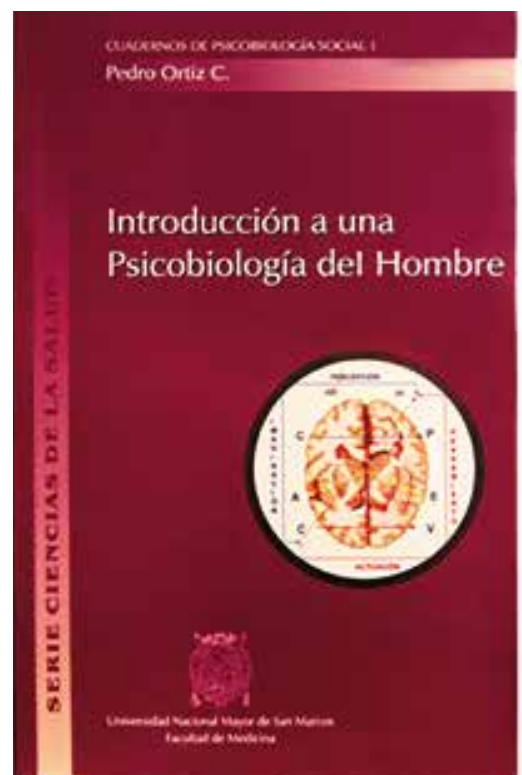

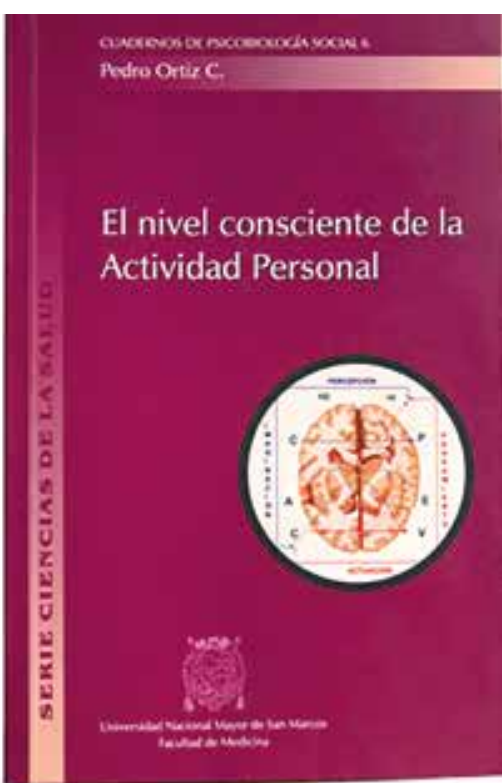

C

\section{B}

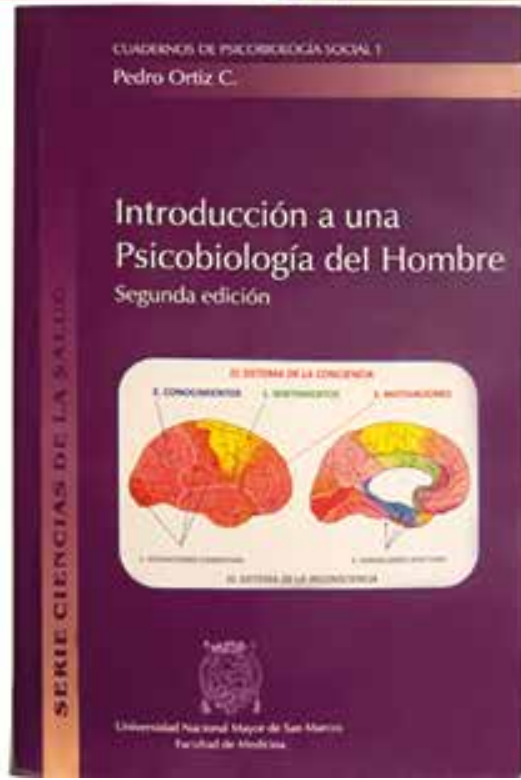


Anexo 7. La aplicación ética. Este libro (2007) muestra la evolución sintética de toda la Teoría Sociobiológica Informacional de Pedro Ortiz Cabanillas. Aquí expone su visión de la historia, sintetiza su explicación de la sociedad y elabora una teoría moral de corte informacional

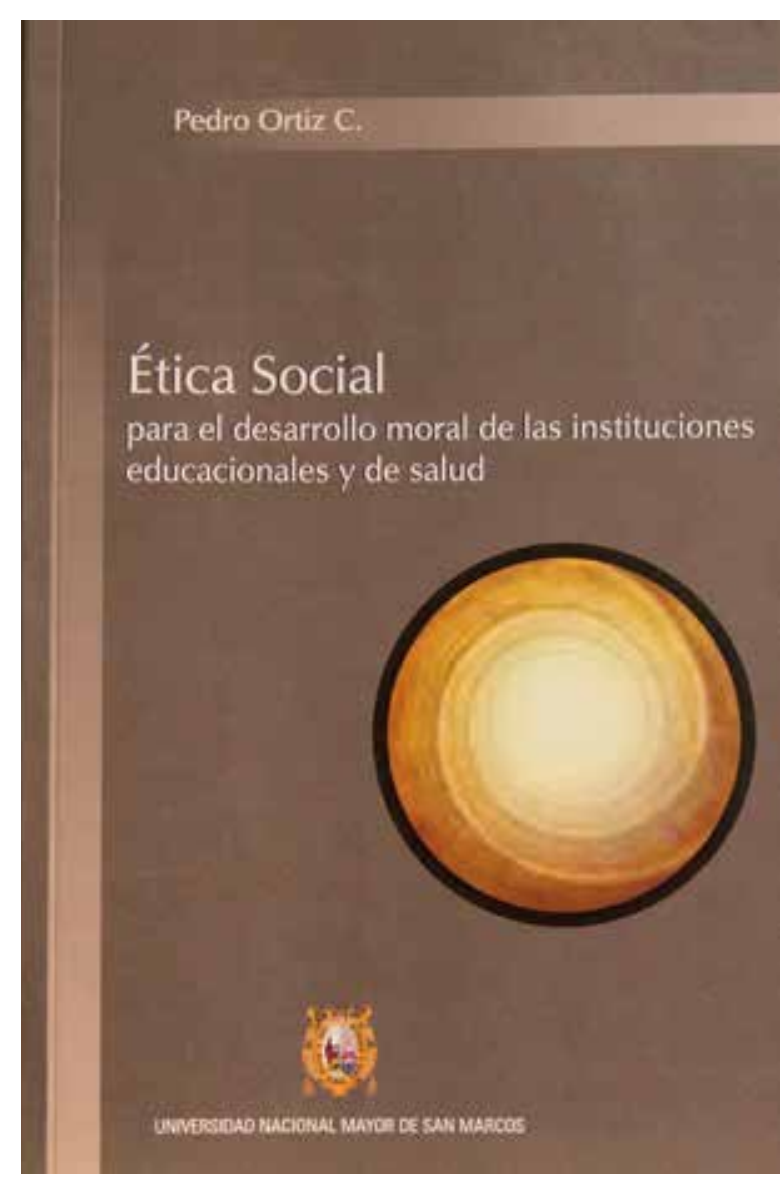


Anexo 8. La obra breve (1984-2011). Estos tres cuadernos, publicados en el 2011, reúnen diez artículos breves publicados entre 1984 y 2011. Esta obra rescató el primer artículo de Pedro Ortiz Cabanillas (escrito en 1984, cuando tenía 51 años) donde empieza a elaborar la Teoría Sociobiológica Informacional.

A

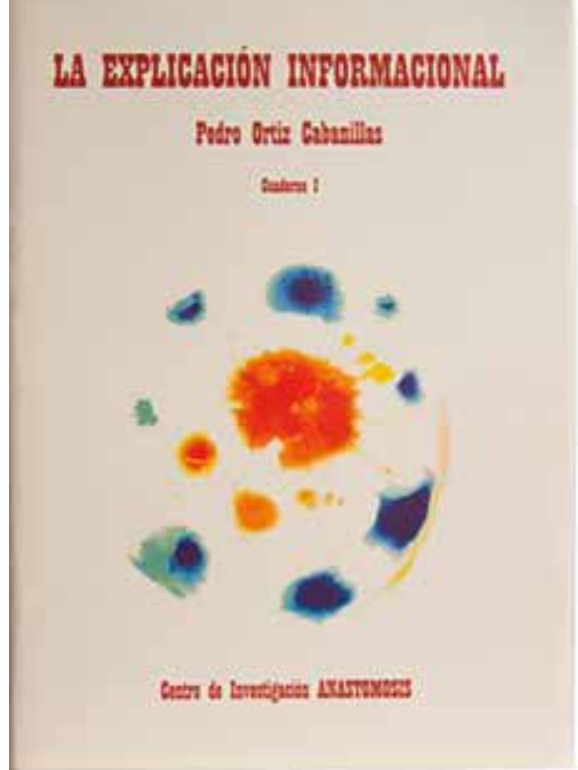

LA EXPLCACHON INFORMAGTONAL

B

\section{LA EXPLEAGION INPORMAGTONAL}

C

Putro oxtic Caturillys

tothen II

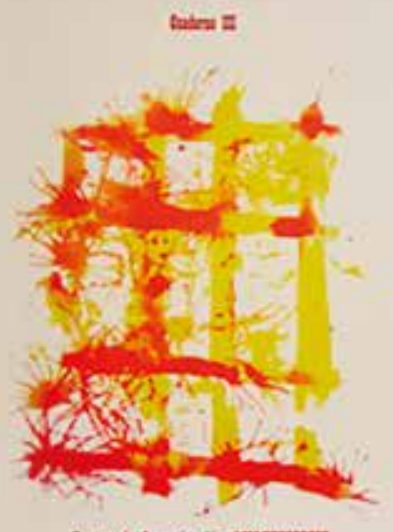

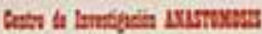


Anexo 9. Este libro (2013) es el primer capítulo del «libro mayor» de Pedro Ortiz Cabanillas (que no llegó a concluir) «Neurociencia Clínica. Una explicación de los trastornos, defectos y deterioros neuropsíquicos de la personalidad»

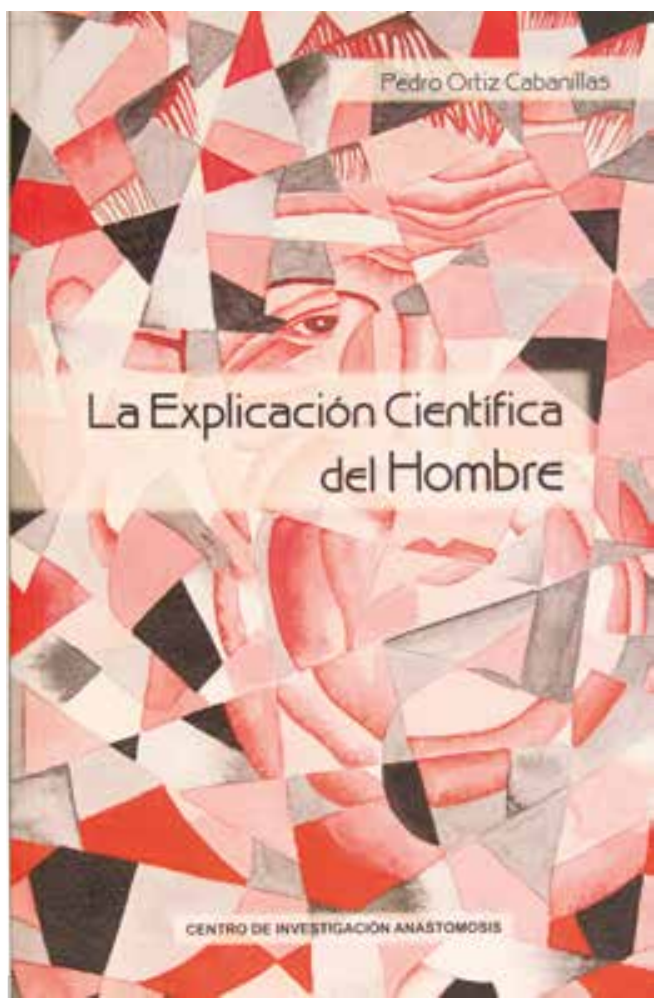


Anexo 10. Miscelánea de artículos breves. La Asociación Tarpuq editó este libro (2014) con objeto de recopilar los artículos que a lo largo de una década se publicaron en la Revista «Maestros». Adicionalmente, la publicación incluye una selección de varios artículos de Pedro Ortiz Cabanillas

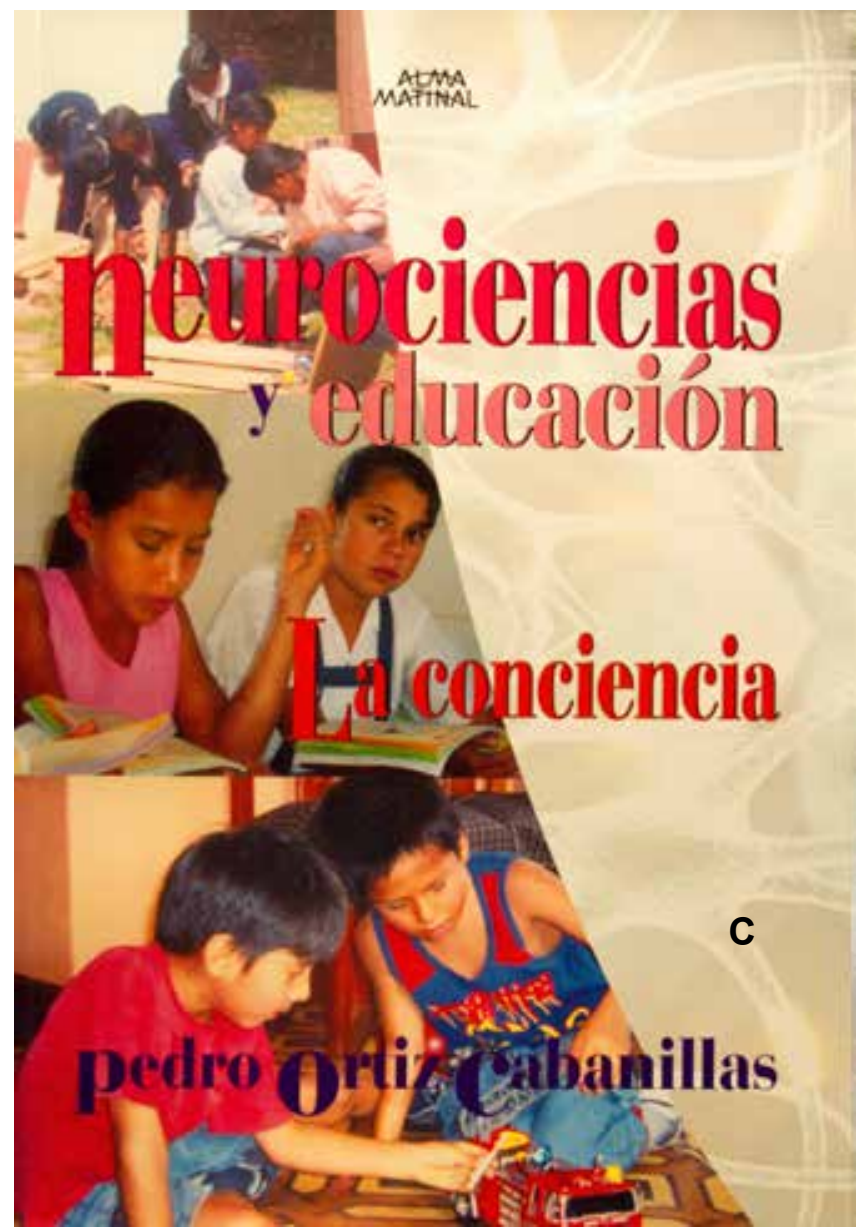


Anexo 11. La edición integral de los Cuadernos de Psicobiología Social. Esta obra (2017) incluye la totalidad de los siete cuadernos de Psicobiología Social.

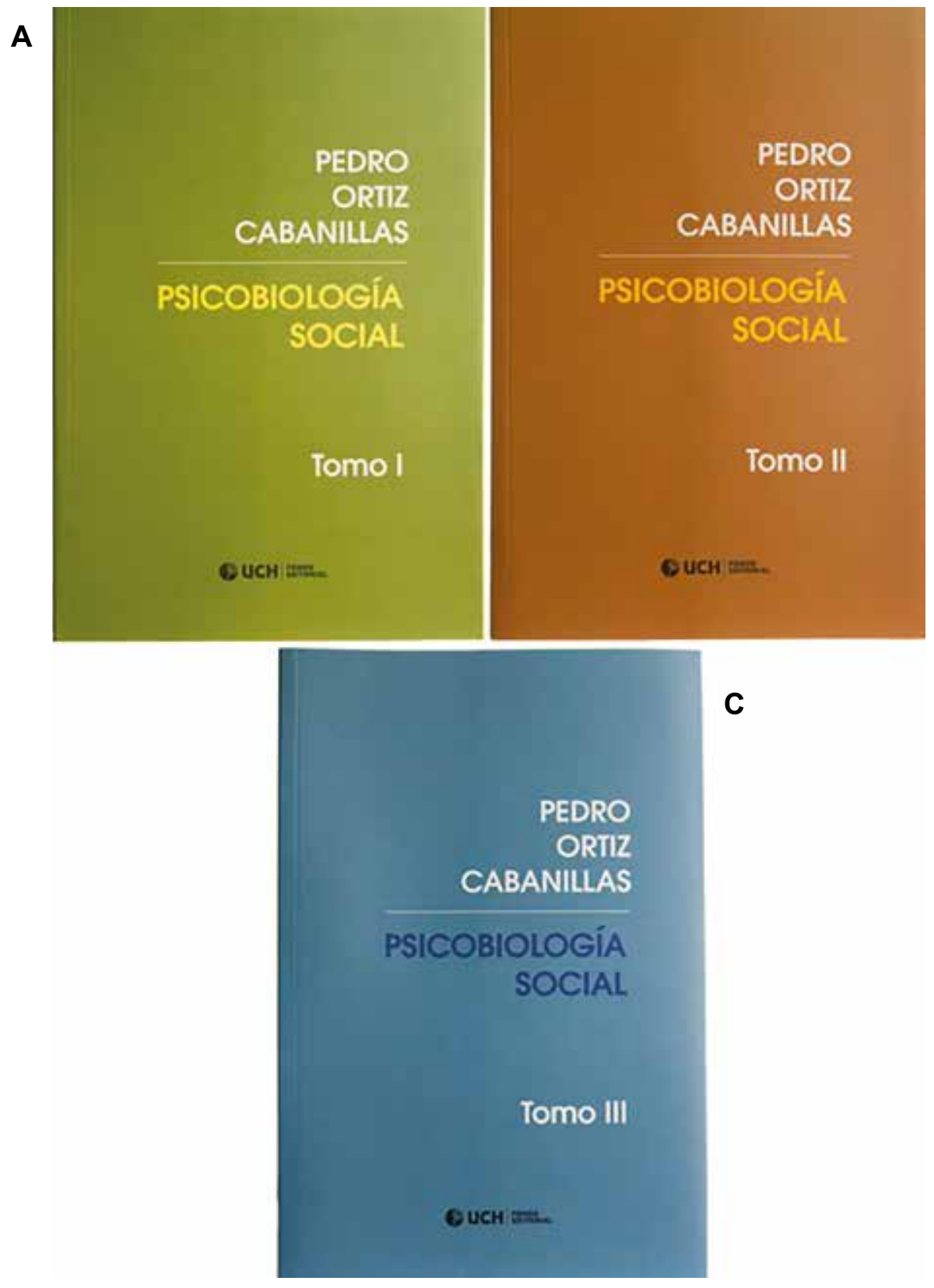

B 